$1 N \cdot \leq 2$

NASA Technical Memorandum 107434

\title{
Feasibility Study of Optically Transparent Microstrip Patch Antenna
}

Rainee N. Simons

NYMA, Inc

Brook Park, Ohio

and

Richard Q. Lee

Lewis Research Center

Cleveland, Ohio

Prepared for the

1997 International Symposium and Radio Science Meeting cosponsored by IEEE, AP-S, and U.R.S.I.

Montreal, Canada, July 13-18, 1997

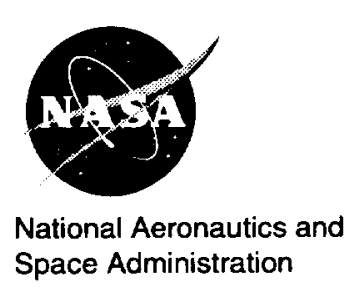




input impedance is shown in figure 6 . The above patterns when compared to those of conventional patch antenna are observed to be similar. Further, the above measurements indicate that it is possible to obtain good impedance match as in the case of conventional patch antenna.

\section{CONCLUSION AND DISCUSSIONS}

The feasibility of constructing an optically transparent patch antenna has been demonstrated. The measured radiation patterns, return loss and input impedance of the antennas have been presented. Based on the above preliminary results we are confident that this concept can be further developed to produce arrays for practical applications.

\section{REFERENCE}

1. Courtaulds Performance Films, AgHT Product Line Data Sheet.
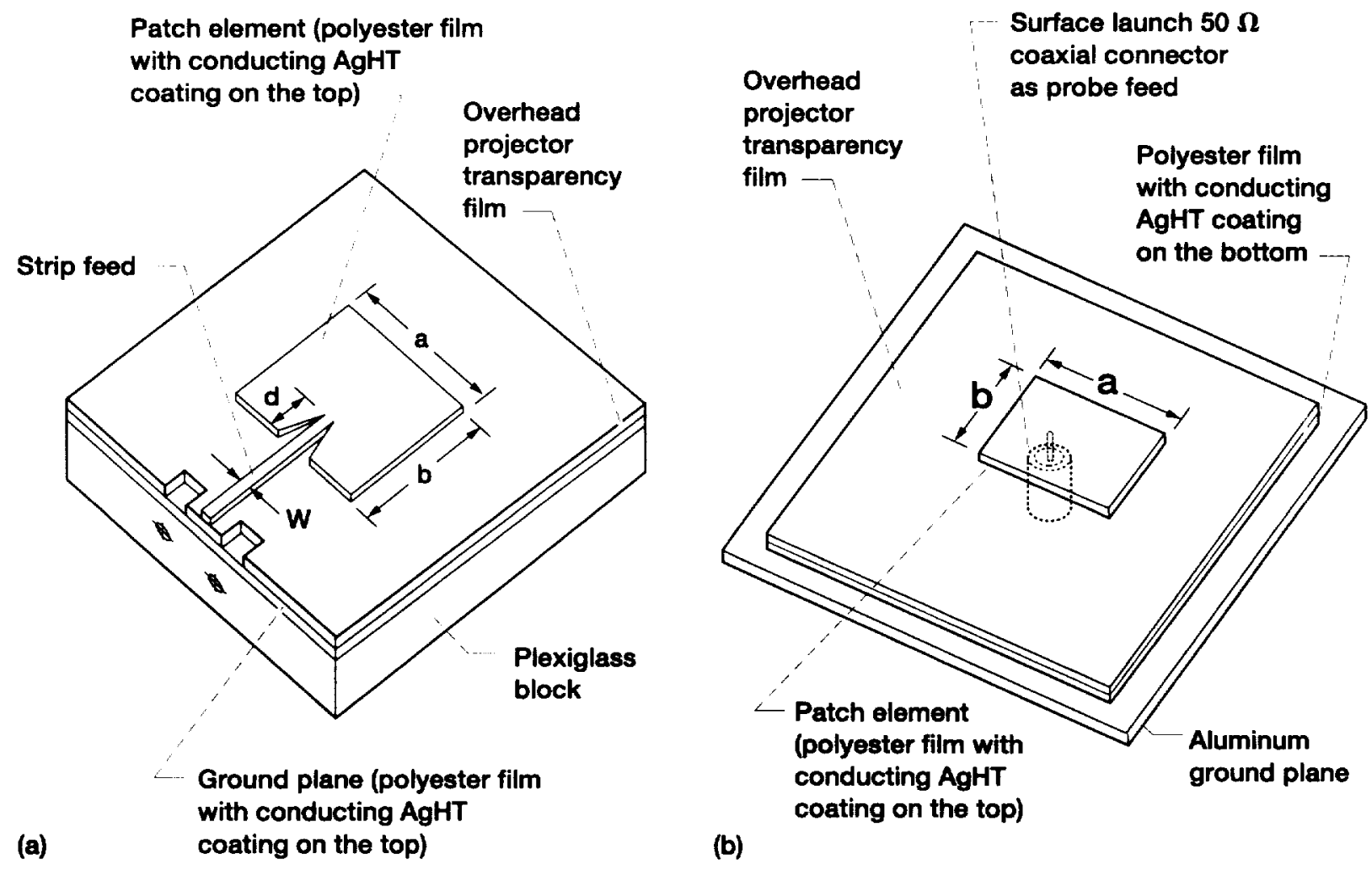

Figure 1. Schematic illustrating the construction of the optically transparent patch antenna. (a) Microstrip line feed. $a=53 \mathrm{~mm}, b=37 \mathrm{~mm}, d=8 \mathrm{~mm}, w=2 \mathrm{~mm}$. (b) Probe feed. $a=9 \mathrm{~mm}, b=7 \mathrm{~mm}$. 


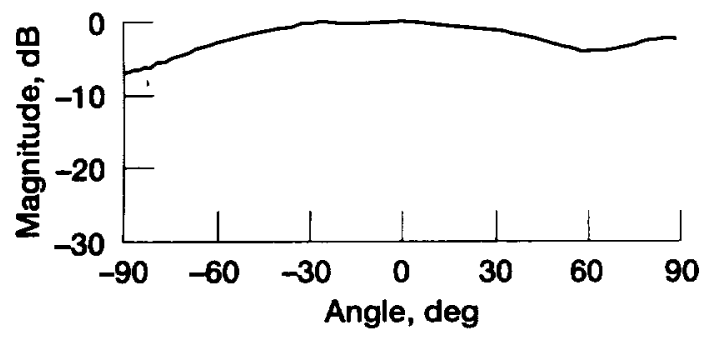

(a)

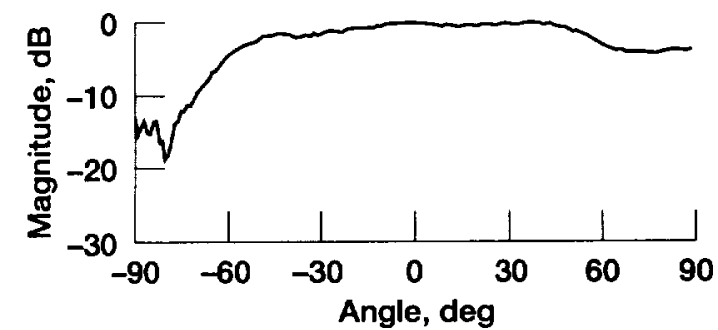

(b)

Figure 2.-Measured radiation pattern of the patch with microstrip feed at 2.3 GHz. (a) E-plane. (b) H-plane.

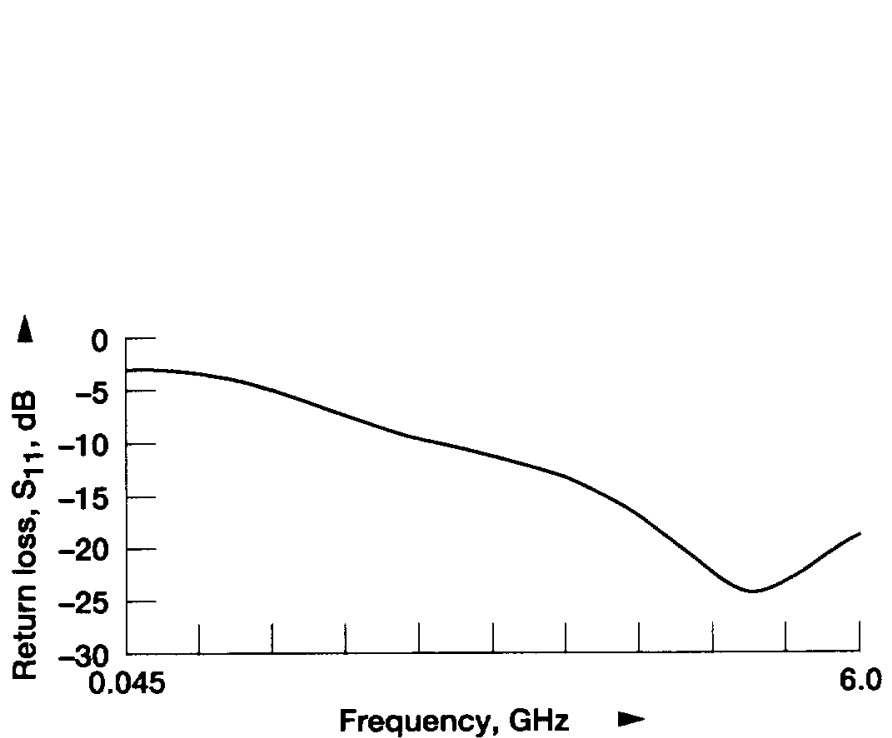

(a)
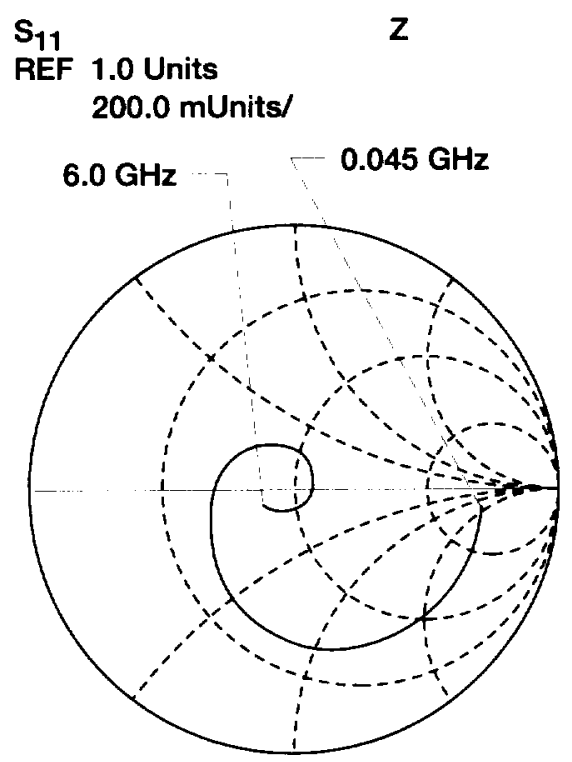

(b)

Figure 3.-(a) Measured return loss of the patch with microstrip feed. (b) Measured input impedance of the patch with microstrip feed.

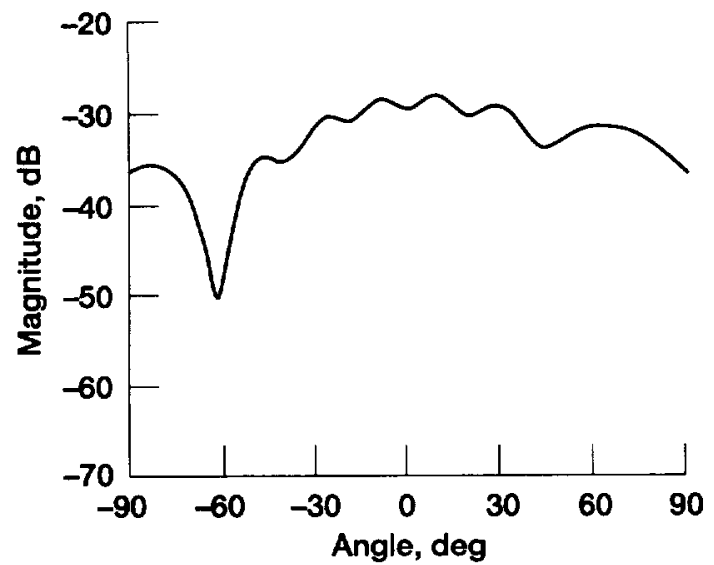

(a)

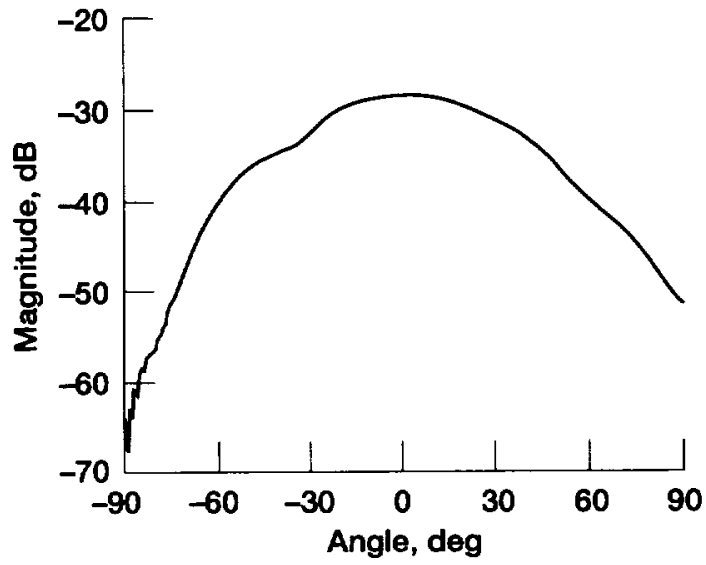

(b)

Figure 4.-Measured radiation pattern of the patch with probe feed at $19.5 \mathrm{GHz}$. (a) E-plane. (b) H-plane. 


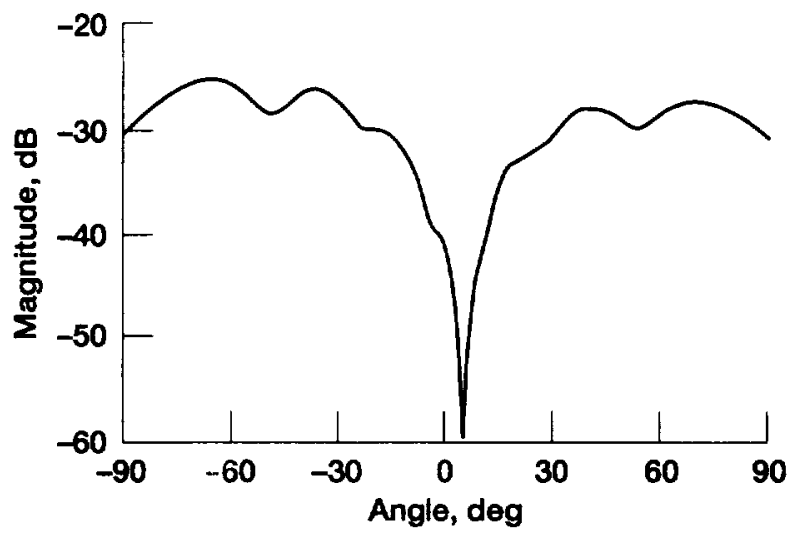

Figure 5.-Measured H-plane cross-polarization of the patch with probe feed.

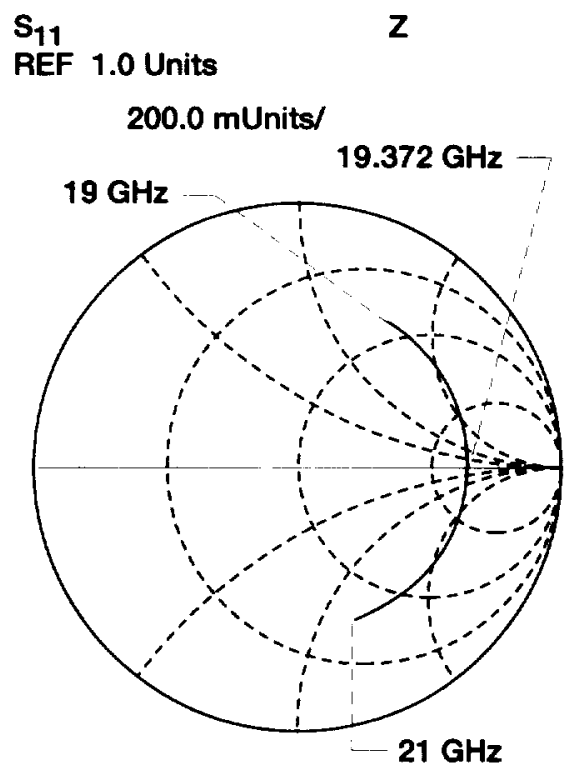

Figure 6.-Measured input impedance of the patch with probe feed. 


\section{.}




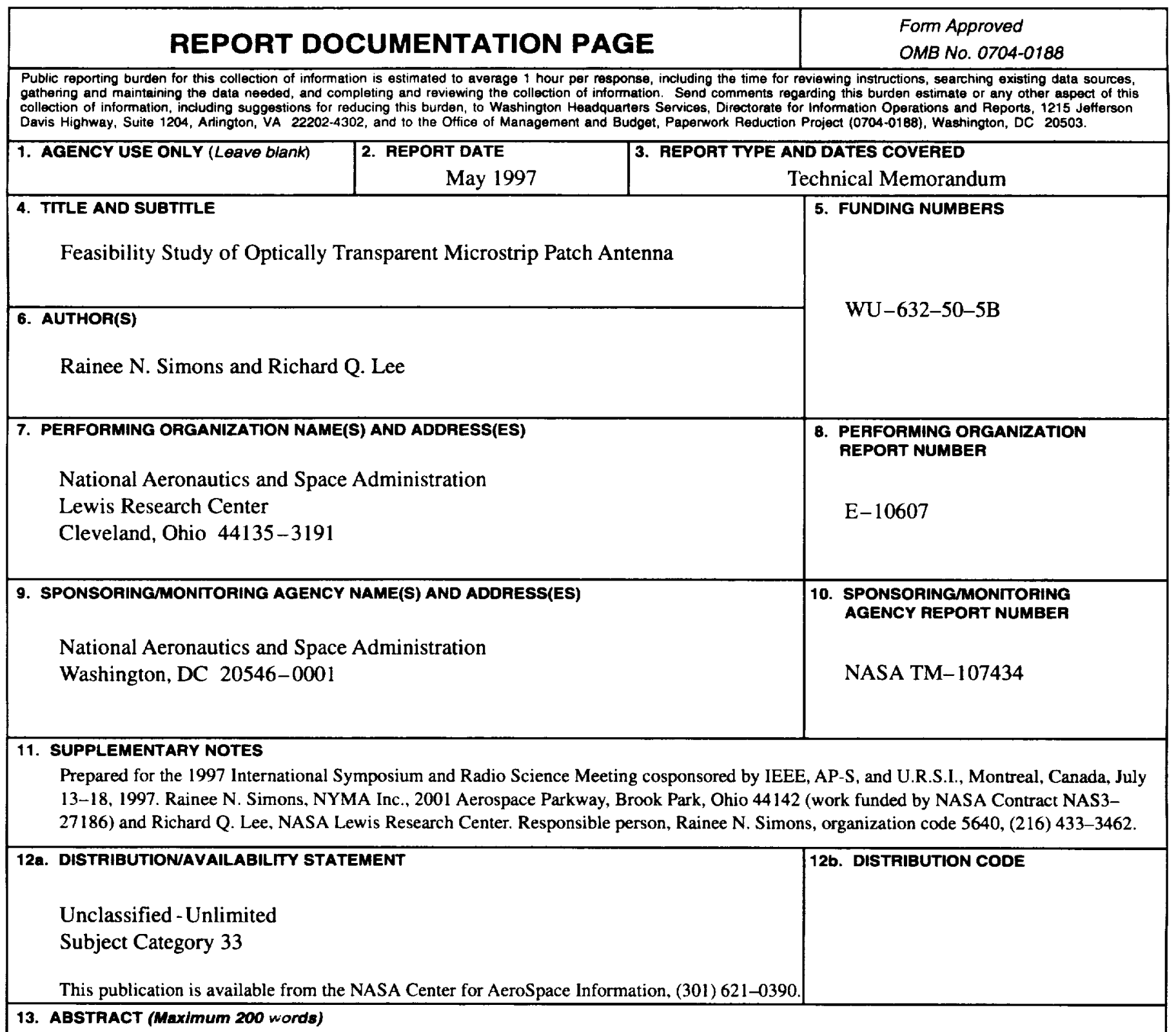

The paper presents a feasibility study on optically transparent patch antennas with microstrip line and probe feeds. The two antennas operate at $2.3 \mathrm{GHz}$ and $19.5 \mathrm{GHz}$ respectively. They are constructed from a thin sheet of clear polyester with an AgHT-8 optically transparent conductive coating. The experimental results show good radiation patterns and input impedance match. The antennas have potential applications in mobile wireless communications.

14. SUBJECT TERMS

15. NUMBER OF PAGES

Optically transparent antenna; Microstrip patch antenna

17. SECURTYY CLASSIFICATION OF REPORT

Unclassified
18. SECURTYY CLASSIFICATION OF THIS PAGE Unclassified
19. SECURITY CLASSIFICATION OF ABSTRACT Unclassified 